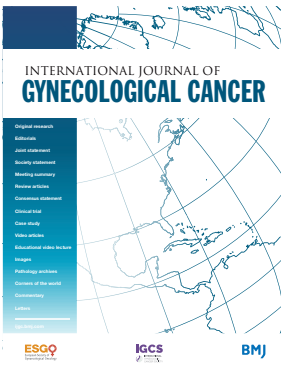

Department of Gynecology Oncology, British Hospital of Buenos Aires, Buenos Aires, Federal District, Argentina

Correspondence to Dr Maria Cecilia Darin, Department of Gynecology, British Hospital of Buenos Aires, Buenos Aires, CP 1280, Federal District, Argentina; ceciliadarin85@gmail.com

Accepted 2 December 2021

\title{
Cervical cancer after LACC: a combination of surgical strategies
}

\author{
Maria Cecilia Darin (iD , Julian Di Guilmi, Johana Quiroga Luna, Antonio Gustavo Maya
}

\section{SUMMARY}

In 2018 the results of an early termination of the LACC trial were published, ${ }^{1}$ followed by several retrospective trials, all showing inferior outcomes of patients with cervical cancer who underwent minimally invasive surgery. After years of training in laparoscopic radical hysterectomy we had go backwards and start learning the open way of surgery again. ${ }^{2}$

This is an educational video showing a combination of strategies and surgical approaches in patients with cervical cancer after the LACC trial

Since we already have the laparoscopic platform for sentinel lymph node mapping with indocyanine green, we decided to start surgeries with minimally invasive surgery. After cervical injection of indocyanine green, we search for the bilateral sentinel lymph nodes. If we see macroscopically suspicious lymph nodes, they are sent to frozen section. The radical hysterectomy is prepared through laparoscopy by dissecting the retroperitoneal space, identifying vascular structures and the ureter. In 2019 to 2020, Dr Kohler and Dr Chiva suggested that closing the vagina over the tumor is a feasible technique that could avoid tumor spillage and might improve outcomes in minimally invasive surgery. ${ }^{34} \mathrm{So}$, we began our learning curve in vaginal cuff in open surgery. Here we show how we infiltrate the vagina, dissect bladder and rectum, and perform a continuous suture.

The procedure is continued by the open way. We coagulate and section the uterine artery and ventral, lateral, and posterior parametrium.

Prospective randomized trials are needed to prove that minimally invasive surgery is safe for our patients with the addition of surgical changes, such as creation of the vaginal cuff and no uterine manipulator. Meanwhile, we continue our radical hysterectomies by the open approach, starting with laparoscopy for the sentinel lymph node dissection and identification of retroperitoneal spaces, with additional time to create the vaginal cuff.

\section{Twitter Maria Cecilia Darin @CeciliaDarin1}

Contributors MCD: Guarantor, writing, review, video editing. JDG and JQL: review and editing. AGM: review.

Funding The authors have not declared a specific grant for this research from any funding agency in the public, commercial or not-for-profit sectors.

Competing interests None declared.

Patient consent for publication Not applicable.

\section{Cervical cancer after LACC trial: A combination of surgical strategies}

Darin MC, Di Guilmi J, Quiroga Luna J, Maya AG

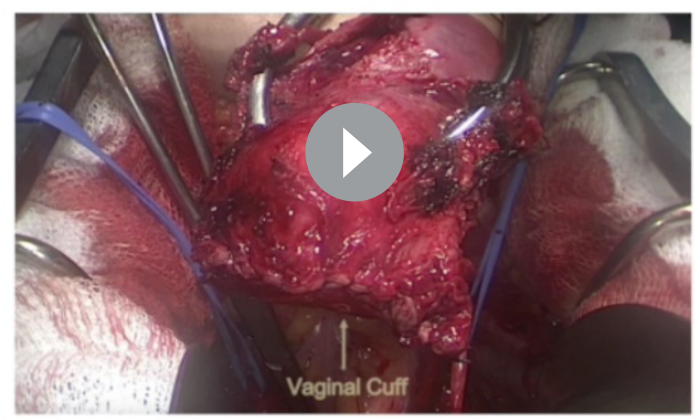

To cite: Darin MC, Di Guilmi J, Quiroga Luna J, et al. Int J Gynecol Cancer Published Online First: [please include Day Month Year]. doi:10.1136/ ijgc-2021-003042

(c) IGCS and ESG0 2021. No commercial re-use. See rights and permissions. Published by 
Video article

Ethics approval This study does not involve human participants.

Provenance and peer review Not commissioned; externally peer reviewed.

Data availability statement Data are available upon request.

ORCID iD

Maria Cecilia Darin http://orcid.org/0000-0003-4833-3501

\section{REFERENCES}

1 Ramirez PT, Frumovitz M, Pareja R, et al. Minimally invasive versus abdominal radical hysterectomy for cervical cancer. $N$ Engl $J$ Med 2018;379:1895-904.
2 Ferrier C, Pellevoizin R, Touboul C, et al. Back to the future: SchautaAmreich radical vaginal hysterectomy assisted by laparoscopy with sentinel lymph node biopsy for early-stage cervical cancer. J Minim Invasive Gynecol 2021;28:131-6.

3 Kohler $\mathrm{C}$, Hertel $\mathrm{H}$, Herrmann J, et al. Laparoscopic radical hysterectomy with transvaginal closure of vaginal cuff - a multicenter analysis. Int J Gynecol Cancer 2019;29:845-50.

4 Chiva L, Zanagnolo V, Querleu D, et al. SUCCOR study: an international European cohort observational study comparing minimally invasive surgery versus open abdominal radical hysterectomy in patients with stage IB1 cervical cancer. Int J Gynecol Cancer 2020;30:1269-77. 